\title{
14 Multiparty Split-Ticket Voting Estimation as an Ecological Inference Problem*
}

Kenneth Benoit, Michael Laver, and Daniela Giannetti

ABSTRACT

The estimation of vote splitting in mixed-member electoral systems is a common problem in electoral studies, where the goal of researchers is to estimate individual voter transitions between parties on two different ballots cast simultaneously. Because the ballots are cast separately and secretly, however, voter choice on the two ballots must be recreated from separately tabulated aggregate data. The problem is therefore of one of making ecological inferences. Because of the multiparty contexts normally found where mixed-member electoral rules are used, furthermore, the problem involves large-table $(R \times C)$ ecological inference. In this chapter we show how vote-splitting problems in multiparty systems can be formulated as ecological inference problems and adapted for use with King's (1997) ecological inference procedure. We demonstrate this process by estimating vote splitting in the 1996 Italian legislative elections between voters casting party-based list ballots in proportional representation districts and candidate-based plurality ballots in single-member districts. Our example illustrates the pitfalls and payoffs of estimating vote splitting in multiparty contexts, and points to directions for future research in multiparty voting contexts using $R \times C$ ecological inference.

\section{INTRODUCTION}

Split-ticket voting is a common focus of interest in the field of electoral studies. It is concerned with identifying and analyzing patterns in the way that voters behave when faced with two distinct voting choices that give them the option of dividing their vote between different parties. Vote-splitting opportunities may be presented by institutional frameworks, such as having two types of votes to cast simultaneously in a mixed-member system; having a runoff election in systems where failure to reach a minimum vote percentage in a first round of elections allows voters a second opportunity to vote in a runoff; or even having the possibility of casting multiple votes for the same office (possibly preferential or transferable votes). Other possibilities for observing vote splitting are presented by votes for separate offices, whether simultaneously elected (as when congressional and presidential elections coincide) or temporally separate (as in estimating voter transitions between two sequential elections).

Faced with the possibility of dividing their vote between parties, voters may choose to maintain a consistent ticket by casting two ballots for the same party, or to split their ticket by voting for different parties on different ballots. The manner in which they split their vote offers observable implications on a wide variety of theoretical explanations of voting behavior, such as the investigation of strategic voting (Laver, 1987), instrumental or expressive

\footnotetext{
* Thanks to Raj Chari, John Haslett and David Jackson for comments, and to Gary King and Jeff Gill for help with the estimation issues.
} 
voting (Benoit, Giannetti, and Laver, 2002), a voter's desire to produce divided government (Fiorina 1996), byproducts of ballot mechanisms (Beck, 1997), the efficacy of campaigning (Burden and Kimball, 1998), or the approval or rejection of potential governments (Strøm, Budge, and Laver, 1994) - making the estimation of split-ticket voting an issue of keen interest to researchers in electoral studies.

The potential wealth of theoretically informative behavior yielded by ticket splitting has been limited, however, by the difficulty of estimating the phenomenon. Because anonymously and separately cast ballots are not linked by any identifying information, the only way to estimate split-ticket voting from actual election results is by using aggregate data. Surveys offer an indirect alternative for measuring individual-level ticket splitting, but these suffer from a variety of additional problems, such as overstating voter turnout and overstating support for winners (see Burden and Kimball, 1998: 534), as well as providing too few cases at the district level to allow for reliable estimation of behavior in the context where the behavior actually takes place. The only directly observable phenomena typically available to researchers, therefore, are voting results aggregated at some unit of electoral geography, such as precinct, district, state, or region. Each electoral unit can then be thought of as providing a table whose rows and columns are defined by voters exercising categories of choice on two separate ballots. The problem created by the anonymity of the voter and the absence of any linking information between the two ballots is that the cell values are unknown. The problem, therefore, is the well-known one of having to make ecological inferences about individual behavior based on aggregate data, requiring statistical techniques appropriate to this problem.

Our attention in this chapter focuses on using techniques of ecological inference to estimate split-ticket voting under mixed-member electoral systems. Used in various forms in New Zealand, Italy, Germany, Russia, and Hungary - to name but a few examples - the mixed-member electoral system provides two distinct political contexts for voting. ${ }^{1}$ One of these is a proportional representation (PR) context in which choices are made in relation to party lists in multimember constituencies. The other is a single-member district (SMD) context in which choices are made in relation $\bar{\equiv}$ individual candidates, typically using a plurality rule. A popular compromise for states $\overline{\bar{x}}$ king a balance between majoritarian and proportional principles, mixed-member systems are now used in a substantial number of post-Communist states as well (Moser, 1999; Shugart and Wattenberg, 2001b). Elections held under mixed-member systems provide political scientists with fascinating natural laboratories within which to analyze the behavior of the same set of voters in different strategic settings under otherwise controlled conditions, confronting the same party system and the same issue space at the same moment in time. Analyses of vote splitting in such systems not only are descriptively interesting to scholars concerned with a particular political system, but have also been used more generally to explore alternative theoretical accounts of voting behavior. Vote splitting has been studied closely in New Zealand, for instance, since its switch from first-past-the-post to that system in 1996 (e.g., Johnston and Pattie, 1999, 2000; Banducci, Karp, and Vowles, 1998). Italy also adopted the mixed-member system for first use in its 1994 election, prompting numerous studies of its effects on voter choice (see Benoit, Giannetti, and Laver, 2002); so did Japan (Reed and Thies, 2001).

The difficulty of estimating split-ticket voting under mixed-member rules, however, is substantially greater than the same problem studied in the traditional U.S. or British contexts. This is because the mixed-member electoral system is almost always associated with a multiparty system. The number of unknowns to be estimated is multiplied by having

1 For an excellent general discussion of mixed-member electoral systems, see Shugart and Wattenberg (2001a). 
more than two or three categories of vote choice on each dimension of the voter transition table. In the language used elsewhere in this book (e.g., Judge, Miller, and Cho, Chapter 7), the ill-posed inverse problem in multiparty split-voting studies is even more ill-posed than in typical two-party applications. Our ability to estimate and analyze split-ticket voting in multiparty contexts, therefore, is directly linked to advances in ecological inference that make reliable and accurate estimates possible.

In what follows we demonstrate how split-ticket voting under mixed-member electoral rules can be expressed as an ecological inference problem and estimated using an extension of King's (1997) ecological inference technique (referred to hereafter as EI) suited for $2 \times C$ tables. Our data comes from the 1996 elections to the Italian Chamber of Deputies, where we have observed both PR and plurality voting by party in a total of 475 single-member districts. First, we frame the problem of vote splitting by partitioning voters according their political preferences and voting behavior. Next, we partition the observable aggregate data into a framework corresponding to the partition of voter types. We then adapt the EI procedure to estimate at the district level the relative proportions of each type of individual voter from the partitioned aggregate data, using the extended EI model incorporating additional contextual information in the form of district-level covariates. In addition to reviewing important diagnostic information from the EI estimations to provide a methodological evaluation of our results, we also analyze and characterize these results in a substantive empirical context. Finally, we offer suggestions for taking the Italian estimates further and for extending our approach to other contexts.

\section{VOTING IN THE ITALIAN MIXED-MEMBER ELECTORAL SYSTEM}

\section{Electoral Politics and Background}

The Italian mixed-member electoral system involves 475 single-member districts, in which candidates compete in plurality elections, as well as 26 multimember constituencies (circoscrizioni), in which a total of 155 seats are allocated by $\mathrm{PR}$, giving a total legislature of 630 seats. $^{2}$ (For a brief but clear description, see D'Alimonte, 1998.) Though the new electoral system was intended to bring about a reduction in the number of parties, what in fact happened was that Italian political parties retained their separate identities, organizing themselves into opposing "cartels" with preelection agreements that shared out the candidacies in the single-member districts. Electoral politics in the 1996 elections had thus been structured around two major electoral coalitions, the Polo della Libertà, on the right, and the Ulivo, on the left. ${ }^{3}$

Since nearly every Italian party also establishes a list to contest the multimember constituencies, almost every Italian voter may vote for his or her most preferred party in the PR element of the election. When it comes to the plurality ballot, however, a voter's first-choice party may well not be contesting the single-member constituency in which the voter lives. It may be replaced instead by another party from the same cartel to which the first-choice

2 The number of PR seats a party will eventually obtain is determined by subtracting the plurality vote share of second-placed candidates in the districts where a party has won a seat from the PR vote share of that party at the constituency level. This is a partial deduction, known as the scorporo.

3 In 1996, the Ulivo consisted of the Greens (Fed. Dei Verdi), the Prodi alliance (Pop-SVP-PRI-UD-Prodi), the Democratic Party of the Left (PDS), the Dini List (PPI), and PS d'Az. Although not formally part of the Ulivo cartel, the Refounded Communists (RC) is also included because of the nature of its exclusivity pacts in 1996, which functioned like the formal cartel agreements. Polo consisted of CCD-CDU, Forza Italia (FI), and the Alleanza Nationale (AN). 
party belongs. The different choices facing voters in single- and multimember constituencies confront Italian voters with important strategic decisions.

\section{A Model of Voting Behavior in Italy's Mixed-Member System}

Our focus in this paper is on substantive and procedural issues pertaining to the estimation of vote-splitting between cartels, rather than the empirical confirmation of a theoretical model of voting behavior. Nonethless, it is useful to distinguish between two broad categories of voters. This is the distinction, introduced by Brennan and Lomaski (1993) and developed by Schuessler (2000) and by Brennan and Hamlin (2000), between instrumental and expressive voters. Essentially, the instrumental value of a vote "derives from the contribution the vote makes to bringing about the desired electoral outcome" (Brennan and Lomaski, 1993: 23). The expressive, or "intrinsic," value of a vote, on the other hand, "is the value that the voter places on expressing a preference for $a$, rather than $b$, in and of itself (i.e., independent of any effect of the voting act on the electoral outcome" (Brennan and Lomaski, 1993: 23; emphasis in original).

The PR element in a mixed-member election provides strong incentives for voters to vote "sincerely" for their most-preferred parties. For most voters, their first-choice party is available on the ballot, giving their vote maximum value as an expression of political preference. For instrumental voters, voting for the first-choice party increases the probability of this party getting into government and changing policy outputs; it increases the party's claim on cabinet seats should it succeed in getting into government, thereby increasing its impact on policy outputs; and it increases the allocation of SMD candidacies within the electoral cartel in future elections, thereby increasing its chances of success in the future. For these reasons, therefore, we assume that voters who have genuine (instrumental or expressive) preferences for a specific political party will always vote for this party on their PR ballot.

The plurality element in the election, on the other hand, may or may not result in one of the two big cartels offering a given voter his or her most-preferred party. If it does offer a voter the most-preferred party, then we assume the voter will also cast his or her plurality vote for this party's candidate. For the same reasons outlined in the previous paragraph, both instrumental and expressive voters are likely to cast their plurality ballot in a partyloyal fashion. This will be true in all constituencies except those in which some third party is predicted to have a serious chance of success. In such constituencies, some voters may face a strategic decision. For some instrumental voters, it may possibly be the case that a voter will do better by voting strategically, not for his or her most-preferred party, but for the party best placed to defeat a less-preferred rival. Otherwise the instrumental voter should still vote for his or her most-preferred party.

A much more common situation in the plurality election is that one of the two big cartels does not offer a voter his or her most-preferred party, but a candidate from another party in the same electoral cartel. We can think of such voters as being disappointed, or frustrated, since their first-choice party is not on offer. The problem examined in this paper consists of estimating the proportions of disappointed voters who behave in one of two possible ways.

One way that disappointed voters can behave is to vote for the candidate sponsored by the cartel of their most-preferred party. For a variety of reasons, voters may choose to cast their plurality vote in this cartel-loyal manner. For disappointed instrumental voters, voting for another party in the same cartel increases the probability that their most-preferred party will be a member of the winning cartel, will go into government, will receive cabinet seats, and will thereby have some impact on public policy. Disappointed instrumental voters thus 
use their vote to have an effect on which cartel wins the election, and hence place their most-preferred party in the strongest position. Disappointed expressive voters, in contrast, are likely to switch their vote to the party on offer that is next highest in their expressive ranking. Since, as we have seen, many matters other than policy may determine expressive returns, this party may or may not be in the same cartel as their first-choice party, but it is quite possible that it is indeed in the same cartel.

The other way that disappointed voters can behave is to switch their votes to a candidate who is outside the cartel of their most-preferred party - in other words, in a cartel-disloyal fashion. Cartel switching is something that might be quite logical for disappointed expressive voters, since expressive returns can be derived from a wide range of matters that are quite unrelated to cartel membership. We note that voting for a noncartel party (one that is not Polo or Ulivo) offers an additional option for cartel disloyalists. For example, a disappointed voter whose most preferred party is in the Polo cartel, upon finding that the Polo cartel sponsored a candidate in her single-member district from a party different from her most preferred, could be cartel-disloyal by voting either for the Ulivo candidate, or for a noncartel candidate (from a party not sponsored by either Polo or Ulivo).

The bottom line is that the nature of Italian elections under the mixed-member electoral system allows us to partition Italian voters into three exclusive and exhaustive sets. The first set consists of people who vote for some party in the PR election and, finding the same party available in the SMD election, vote for it again. We call these voters party loyalists. The second set consists of voters who vote in the PR election for their most preferred party and, finding this party unavailable in the SMD election, vote for a different party in the same electoral cartel as their most preferred party. We term these voters cartel loyalists. The third set comprises those who vote in the PR election for some party and, finding this party unavailable in the SMD election, vote for a party that is not in the same electoral cartel as their PR choice. We term this final category of voters cartel disloyalists. Having defined the basic types of voter we consider, we now need to define some quantities that will allow us to partition the observed aggregate data.

\section{Formal Statement of the Model}

For each SMD in Italy we define, and can observe, the following quantities:

$N \quad$ The total number of votes in the district. ${ }^{4}$

$P_{u} \quad$ The plurality vote for the candidate running under the Ulivo cartel label.

$P_{p} \quad$ The plurality vote for the candidate running under the Polo cartel label.

$P_{o} \quad$ The sum of the plurality vote(s) for the candidate(s) running under other cartel or noncartel party labels, defined as $N-P_{u}-P_{p}$.

$L_{u} \quad$ The list votes (at the district level) for the party endorsing the candidate running as Ulivo.

$L_{p} \quad$ The list vote (at the district level) for the party endorsing the candidate running as Polo.

$L_{o} \quad$ The sum of the list votes (at the district level) for the parties endorsing the candidates that are running as neither Ulivo nor Polo.

4 Because the number of valid votes differs for each ballot type in a single district, the total number of valid candidate SMD votes seldom equals exactly the total number of valid list votes cast in that SMD. See below for how we deal with this problem. 
$C_{u} \quad$ The sum of the list votes (at the district level) for all parties in the Ulivo cartel.

$C_{p} \quad$ The sum of the list votes (at the district level) for all parties in the Polo cartel.

$C_{o} \quad$ The sum of the list votes (at the district level) for all parties in neither Ulivo nor Polo cartels, defined as $N-C_{u}-C_{p}$.

Following the general argument in Section 14.2, we make the following assumptions about voting behavior:

1. Party-based preference: Each voter has a first preference for one of the political parties contesting the PR element of the election.

2. PR-list vote: Each voter's PR-list vote is a sincere revelation of this preference.

3. SMD vote: Voters cast their candidate-based ballots in the following manner:

(a) Party-loyal voting: If the voter's first-preference party has a candidate in the SMD, then the voter votes for this candidate. This implies that $P_{i} \geq L_{i} \forall i{ }^{5}$

(b) Cartel-loyal voting: If the voter's first-preference party does not have a candidate in the SMD, then a cartel-loyal voter supports the candidate sponsored by the cartel to which the voter's first-preference party belongs. We denote cartel-loyal voters as $y_{p}, y_{u}$, and $y_{o}$, for Polo-, Ulivo-, and other-cartel-loyal voters, respectively.

(c) Cartel-disloyal voting: If the voter's first-preference party does not have a candidate in the SMD, then a cartel-disloyal voter supports a candidate other than the one sponsored by the cartel to which his or her first-preference party belongs. We denote by $d_{i j}$ the fraction of the cartel-disloyal, frustrated voters whose most preferred party is from cartel $i$ who switched their SMD vote to a party from cartel $j(i \neq j)$. Hence, of the cartel-disloyal voters who voted for a Polo candidate in the PR election, $d_{p u}$ denotes the fraction switching to an Ulivo candidate, and $d_{p o}$ the fraction switching to an other-cartel candidate. Proportions of other groups of cartel-disloyal voters are denoted in a similar way.

We can thus completely partition the vote in a single-member district as in Table 14.1. In each SMD the total number of votes, $N$, is partitioned both by the PR-list ballots for cartel parties $\left(C_{p}, C_{u}\right.$, and $\left.C_{o}\right)$ and by the plurality ballots for cartel parties $\left(P_{p}, P_{u}\right.$, and $\left.P_{o}\right)$. According to assumption 3(a), any intersection of $\left(C_{i}, P_{i}\right)$ in Table 14.1 will contain $L_{i}$, since all voters whose preferred party has a candidate will vote loyally for that candidate in the SMD. The intersection $\left(C_{i}, P_{i}\right)$ will contain the cartel-loyal voters who, not having found a candidate from their most preferred party in the SMD, voted for another party's candidate but from the same cartel as their most-preferred party. By definition, the other cells on this row must be empty. The remainder of the plurality vote $P_{i}$ will consist of cartel-disloyal voters who, not having found a candidate from their most preferred party in the SMD, will have voted for cartel $i$ candidate instead; their proportions are denoted by $d$ with a double subscript indicating their most preferred party's cartel and the cartel to which they switched their vote.

Given the partition of voter types and our parameterization of the quantities to be estimated, mapped to the partition of observed aggregate data, we now turn to the problem of estimating the quantities $y$ and $d$.

5 This is true in all cases for the two main cartels, although there are seven marginal exceptions for the residual other-cartel category. Our treatment of the other category below makes this irrelevant, as explained in the next section. 


\begin{tabular}{|llccc|}
\hline \multirow{2}{*}{ Table 14.1 Composition of SMD vote $P$ and list cartel vote $C$ in a SMD } \\
\cline { 3 - 5 } Cartel list vote & Vote type & \multicolumn{3}{c|}{ Cartel plurality vote } \\
\cline { 3 - 5 }$C_{p}$ & $P_{p}$ & $P_{u}$ & $P_{0}$ \\
& Party-loyal & $L_{p}$ & 0 & 0 \\
& Cartel-loyal & $y_{p}$ & 0 & 0 \\
$C_{u}$ & Cartel-disloyal & 0 & $d_{p u}$ & $d_{p o}$ \\
& Party-loyal & 0 & $L_{u}$ & 0 \\
& Cartel-loyal & 0 & $y_{u}$ & 0 \\
$C_{0}$ & Cartel-disloyal & $d_{u p}$ & 0 & $d_{u o}$ \\
& Party-loyal & 0 & 0 & $L_{o}$ \\
& Cartel-loyal & 0 & 0 & $y_{0}$ \\
& Cartel-disloyal & $d_{o p}$ & $d_{o u}$ & 0 \\
\hline
\end{tabular}

\section{A FRAMEWORK FOR ESTIMATING VOTE-SPLITTING IN ITALY}

\section{Reexpressing the Estimation Problem}

Because we observe the quantity $L_{i}$ in each district, and because it forms part of of both the row and column totals, we can remove it from the vote partition described in Table 14.1 by simply subtracting it from $C_{i}$ and $P_{i}$. This emphasizes what we have called frustrated voters: those whose most-preferred party had no candidate in the SMD. The new formulation also highlights the two sources of votes received by each cartel $i$ candidate from its assumed core of party-loyal voters $y_{i}$. First, each cartel $i$ will lose some frustrated voters (represented by $d_{i j}$ and $d_{i k}$ ), who transfer their votes to the other two cartels $j$ and $k$. Second, each cartel $i$ will also pick up some excess votes (represented by $d_{j i}$ and $d_{k i}$ ) from frustrated, carteldisloyal voters from cartels $j$ and $k$. Following this, we define the quantities as $F_{i}$ and $E_{i}$ as follows:

$$
\begin{array}{ll}
F_{p}=C_{p}-L_{p}, & E_{p}=P_{p}-L_{p} \\
F_{u}=C_{u}-L_{u}, & E_{u}=P_{u}-L_{u} \\
F_{o}=C_{o}-L_{o}, & E_{o}=P_{o}-L_{o} .
\end{array}
$$

The F's represent frustrated voters whose most-preferred party has no candidate in the single-member district and who therefore have transferred their vote to another party in the SMD. The E's represent the excess votes received by a plurality candidate over his or her loyal core of voters who cast a list ballot for that candidate's party.

Since the vote total $N$ now reflects the subtraction of $L_{p}, L_{u}$, and $L_{o}$, we denote by $N^{T}$ the total transferred votes, so that $N^{T}=N-\sum L$. We use this designation to reflect the adjustment of the excess votes for the difference between invalid votes in the two ballots. ${ }^{6}$

\footnotetext{
6 A common problem in estimating split-ticket voting is that the observed totals of valid votes for different ballot types always differ slightly, mainly because of different rates of invalid ballots. As a remedy we took $N$ and $N^{T}$ in each district to be the midpoint between the two ballot totals, which we denote $N^{T *}$. No adjustment was needed for the marginals, since we took the relevant input quantities required for input to EI simply as the proportions of the respective ballot totals before averaging the two ballots. Our tests showed that there was no systematic pattern to the differences between ballots, and that the mean of these differences was statistically indistinguishable from zero.
} 


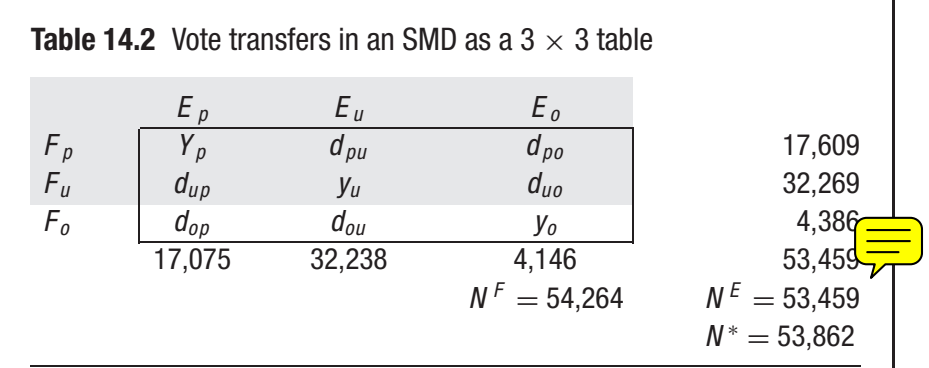

Note: The shaded region provides the $2 \times 3$ subtable which we estimate after eliminating the third row by the simplifying assumption.

This reduces the partition of voting patterns for each district to the $3 \times 3$ matrix shown in Table 14.2. The empirical question in which we are interested now becomes one of estimating the differential levels of cartel-loyal versus cartel-disloyal voting, and in comparing these by cartel. For frustrated voters whose most preferred party was a Polo cartel member, for instance, how many voted for the Ulivo candidate (represented by $d_{p u}$ ) and how many voted for a candidate from neither cartel (represented by $d_{p o}$ )? Because we can observe only the marginals of this table in voting data, the problem becomes one of making ecological inferences about the unobserved cell quantities.

\section{Reducing the Parameter Space}

The problem expressed in the Table 14.2 is one of EI, since it characterizes individual-level voting behavior where only aggregate vote quantities are observed. To estimate the cells at the district level, we use a two-stage application of King's (1997) EI algorithm. Because this method does not work with $3 \times 3$ tables such as Table 14.3, however, we need an additional assumption.

Simplifying Assumption: Voters preferring a party that is not in either the Polo or the Ulivo cartel will always be considered expressive, since only Polo and Ulivo have a chance of winning the election overall. Such voters thus do not have a strategic option that allows them to transfer within a cartel that might win the election. This implies that among

\begin{tabular}{|c|c|c|c|c|c|}
\hline & $\begin{array}{l}\operatorname{Pr}\left(E_{p}\right) \\
b\end{array}$ & $\operatorname{Pr}\left(E_{u}\right)$ & & $\operatorname{Pr}\left(E_{0}\right)$ & \\
\hline $\begin{array}{l}\operatorname{Pr}\left(F_{p}\right) \\
\operatorname{Pr}\left(F_{u}\right)\end{array}$ & $\begin{array}{l}\lambda_{i}^{b} \\
\lambda_{i}^{w}\end{array}$ & $\begin{array}{l}1-\lambda_{i}^{b} \\
1-\lambda_{i}^{w}\end{array}$ & $\begin{array}{l}\beta_{i}^{b} \\
\beta_{i}^{w}\end{array}$ & $\begin{array}{l}1-\beta_{i}^{b} \\
1-\beta_{i}^{w}\end{array}$ & $\begin{array}{l}{\left[X_{i}\right]} \\
{\left[1-X_{i}\right]}\end{array}$ \\
\hline & {$\left[V_{i}\right]$} & & {$\left[T_{i}\right]$} & {$\left[1-T_{i}\right]$} & \\
\hline
\end{tabular}

Note: $\operatorname{Pr}\left(F_{p}\right)$ refers (e.g.) to the proportion of frustrated Polo supporters voting for the Polo candidate, rather than the whole numbers. The quantities in brackets are in King's (1997: 30) notation: $X_{i}$ refers to the proportion of frustrated Polo voters, $T_{i}$ is the proportion of cartel (non-other) voters, and $V_{i}$ is the Polo proportion of non-other-cartel voters. 
Table 14.4 Quantities to be estimated and transformations required from King's parameterization

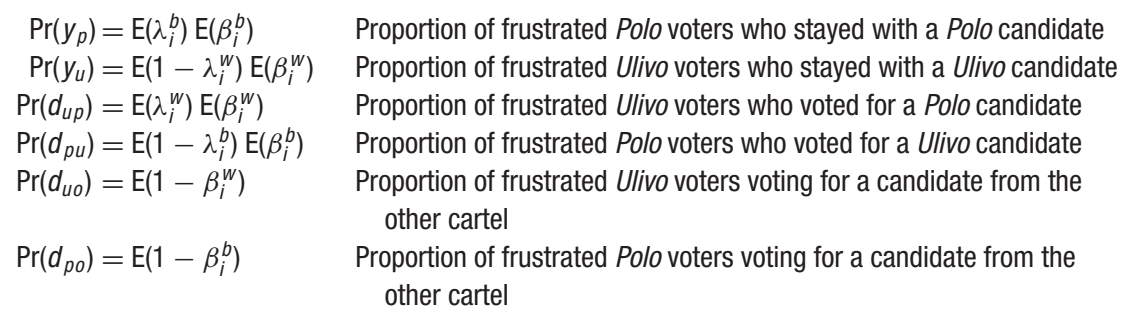

noncartel voters, cartel loyalty or disloyalty - if it applies at all - is not expected to exhibit any systematic pattern. We therefore assume that $d_{o p}, d_{o u}$, and $y_{o}$ are equal, and assign them their expected values $(r c) / n$, or $\left(F_{i} E_{j}\right) / N^{T}$.

Subtracting the row containing $d_{o p}, d_{o u}$, and $y_{o}$ from the $E$ marginals yields the $2 \times 3$ subtable in the shaded region, with a new table total and new totals for the column quantities once the expected values of the third-row frequencies have been computed and subtracted from the relevant column marginals. These new marginals produce the information for an application of EI to the $2 \times 3$ table in a two-stage procedure, estimating the quantities shown in Table 14.3. These four parameters can be estimated by using King's EI software ${ }^{7}$ and the second-stage EI2 procedure for the nested tables. Furthermore, because the precinct-level quantities (here, the electoral unit of the single-member district) can be simulated from the posterior distribution of the main model estimation, EI and EI2 will yield separate estimates of each quantity in each precinct, with corresponding standard errors indicating the uncertainty of each estimate. ${ }^{8}$

Because the parameters $\beta_{i}^{b}, \beta_{i}^{w}, \lambda_{i}^{b}$, and $\lambda_{i}^{w}$ do not directly represent the row proportions we are interested in estimating, they must be transformed into our quantities of loyal and disloyal voting. Table 14.4 shows the simple algebraic transformation required to yield the direct split-voting quantities of interest. From each stage of EI, we saved the 1,000 simulations of each precinct's simulated values of the quantities $\beta_{i}^{b}, \beta_{i}^{w}, \lambda_{i}^{b}$, and $\lambda_{i}^{w}$, transforming them through multiplication of the simulated quantities saved from the output of the EI software. This then yielded in the case of each transformed quantity a vector of 1,000 transformed simulations whose means were used for the point estimates for the precinct-level estimates of $y_{p}, d_{p u}, d_{p o}, d_{u p}, y_{u}$, and $d_{u o}$ (each transformed into column proportions).

\section{Aggregation Bias and Covariates}

Because there are numerous factors that we believe will affect the distribution of the parameter values, we also included covariates in our estimation of the EI quantities. Aggregation bias, as discussed by King (1997) and Voss (this book, Chapter 3) is a problem that occurs when parameter values in specific precincts differ from the general pattern aggregated to the district level. In the Italian data and in studies of split-ticket voting generally, however, not

7 Or Benoit and King's EzI software. See http://Gking. Harvard. Edu/software. shtml

8 When discussing King's EI estimation, we use the term "precinct" to refer to our unit of observation, which is the single-member district. In King's (1997) terminology, the precinct is the minor unit where aggregate behavior is recorded, and the district is the larger unit containing the precincts. 
only do we expect precinct-level parameters to vary substantially, but indeed it is precisely this variation and the patterns within it that motivate the attempt to estimate the split voting. When this variation can be mapped systematically to other variables, we can improve the EI estimates considerably by including precinct-level covariates. For these reasons we employ the extended EI model using covariates that we expect to explain systematic variation in split-ticket voting at the precinct level.

Particularly in Italy, previous work has indicated that electoral choices can only be understood at the level where they are exercised (Shin and Agnew, 2001). Although party campaign strategies are broadly conducted at the national level, they are implemented at local level and "are likely to be a response to the immediate settings, conditions, and circumstances in which political parties operate" (Shin, 2001). More generally, many of the explanations for vote splitting relate specifically to the local electoral unit where vote splitting may occur. These include the existence of specific party candidates, the competitiveness of a precinct, or the intensity of campaign in a precinct - we would expect these factors to cause precinct-level parameters to vary. By including precinct-level measures of such influences as covariates, therefore, we can improve the estimates of our quantities of interest by introducing additional information available to us from our knowledge of split-ticket voting and from the specific Italian political context.

The covariates we include in the EI estimation of cartel-loyal and cartel-disloyal voting are the following:

Intercartel competitiveness. This variable represents the closeness of the Ulivo and Polo cartel list votes $\left(C_{u}\right.$ and $\left.C_{p}\right)$. It is calculated as the absolute difference of $C_{u}$ and $C_{p}$, divided by the total of list votes $\left(\sum C\right)$. Lower values indicate greater intercartel competitiveness, with the distribution of votes between cartels being more even; likewise, higher values indicate that one cartel had a greater lead over the other and that the district was less competitive between cartels. Our expectation is that higher levels of competitiveness (indicated by smaller values of this variable) will cause higher levels of cartel-loyal voting, as the district is more intensely divided and the election outcome both more contested and more uncertain.

Intracartel fragmentation. This variable, measured separately for both Ulivo and Polo, measures the dispersion of the list PR votes among the parties in each cartel. It consists of the ratio of the effective number of parties in the cartel to the actual number of parties. The effective number of parties is measured as $1 / \sum v_{i}^{2}$ each party $i$ in the cartel. When all of the cartel party's votes are equal, the effective number of parties will equal the actual number of parties. The intracartel fragmentation variable thus ranges from a theoretical 0 to 1 , with higher values indicating greater intracartel fragmentation. Our expectation (generally following Tsebelis, 1988) is that greater levels of fragmentation increase intracartel rivalry, decreasing cartel cohesion and cooperation and hence cartelloyal voting. This variable is measured at the level of the single-member district.

Dummy variables. In addition to the competitiveness variables, we also included a number of binary variables to represent qualities specific to each plurality district.

Northern district. When coded as 1 , this indicated that the district was in the Northern region. ${ }^{9}$

9 Other regions included Central, South, and Islands. We did not include any of these regions as covariates, because neither our prior expectations nor subsequent testing gave us reason to believe that they should explain differences in cartel-loyal and -disloyal voting. 
Table 14.5 Aggregate ecological inference estimates, 1996 Italian election data

\begin{tabular}{|c|c|c|c|c|}
\hline Quantity & Point Estimate & S.E. & Lower bound & Upper bound \\
\hline \multicolumn{5}{|l|}{ First-stage El } \\
\hline$\beta^{b}$ & 0.9261 & 0.0005 & 0.8878 & 0.9991 \\
\hline$\beta^{w}$ & 0.9647 & 0.0004 & 0.9010 & \\
\hline$N$ & 465 & & & 0.9980 \\
\hline Simulations & 1,000 & & & \\
\hline Log likelihood & 1522.2528 & & & \\
\hline \multicolumn{5}{|c|}{ Second-stage EI } \\
\hline$\lambda^{b}$ & 0.8748 & 0.0014 & 0.0885 & 0.9199 \\
\hline$\lambda^{w}$ & 0.0468 & 0.0012 & 0.0157 & 0.7052 \\
\hline$N$ & 465 & & & \\
\hline Simulations & 1,000 & & & \\
\hline Log likelihood & 1253.0066 & & & \\
\hline \multicolumn{5}{|c|}{ Transformed model quantities of interest } \\
\hline $\begin{array}{l}\text { Transformed } \\
\text { parameter } \\
\text { (proportions) }\end{array}$ & $\begin{array}{l}\text { Aggregate } \\
\text { estimate }\end{array}$ & S.E. & \multicolumn{2}{|c|}{ 95\% confidence interval } \\
\hline$y_{u}$ & 0.9196 & 0.0012 & 0.9171 & 0.9219 \\
\hline$y_{p}$ & 0.8102 & 0.0014 & 0.8075 & 0.8130 \\
\hline$d_{u p}$ & 0.0451 & 0.0012 & 0.0428 & 0.0474 \\
\hline$d_{p u}$ & 0.1159 & 0.0013 & 0.1132 & 0.1185 \\
\hline$d_{u o}$ & 0.0353 & 0.0004 & 0.0345 & 0.0362 \\
\hline$d_{p o}$ & 0.0739 & 0.0005 & 0.0729 & 0.0749 \\
\hline
\end{tabular}

Northern League candidate. A score of 1 on this variable indicated that a candidate of Lega Nord competed in the plurality contest (as an "Other," or noncartel, candidate). Such candidacies occurred only in the Northern region.

Communist candidate. A score of 1 on this variable indicated that a candidate of the Refounded Communist Party (Rif. Com.) competed in the plurality contest.

Neo-fascist candidate. A score of 1 on this variable indicated that a candidate of Mov. Soc. competed in the plurality contest.

Incumbency variables. Coded for each cartel, the Polo, Ulivo, and noncartel incumbency variables were scored 1 if a candidate competing in 1996 from the respective cartel had won a plurality contest in the 1994 election.

\section{RESULTS}

The results from our estimation of the unobserved quantities of interest appear in Table 14.5. The upper panel of this table displays the aggregate-level EI parameters expressed in 


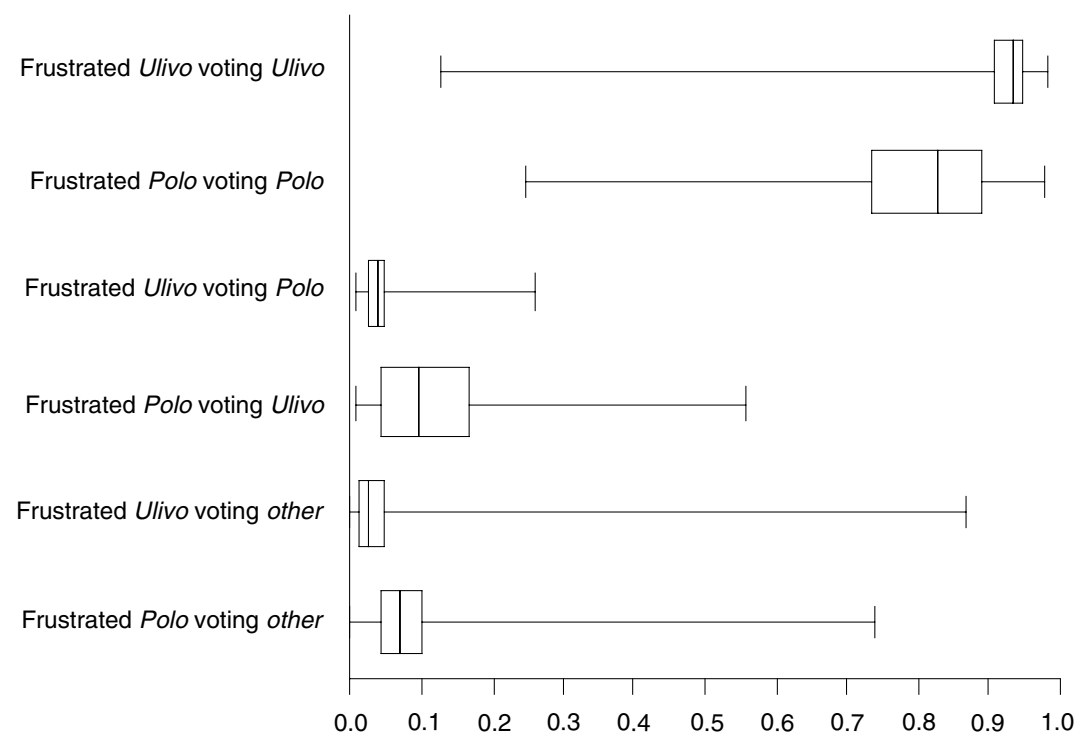

Figure 14.1. Comparing cartel switching and loyalty between Ulivo and Polo cartels.

the scale of estimation, along with information from the estimation procedure such as the number of cases, simulations, and log likelihood. ${ }^{10}$ The lower panel displays the quantities in which we are directly interested, the transformed model quantities of interest (expressed as proportions). The first two quantities we estimate are the degree of cartel loyalty for plurality voters from the Polo and Ulivo cartels ( $y_{p}$ and $y_{u}$ respectively). Here we see strong evidence that the Polo cartel voters were less cohesive than their Ulivo counterparts, with an estimated aggregate proportion of .92 of the frustrated Ulivo voters choosing the Ulivo candidate in the plurality election, compared to an aggregate proportion of .81 of the frustrated Polo voters staying with the Polo-sponsored candidate. Because of of our covariates, furthermore, the bounds on these point estimates are very small indeed, yielding very precise aggregate estimates of cartel loyalty as indicated by the $95 \%$ confidence intervals. ${ }^{11}$

The aggregate rates of between-cartel defection reveal a similar pattern. The estimate of $d_{u p}$, representing the proportion of frustrated Ulivo voters who voted for the Polo-sponsored candidate in the plurality elections, was just 0.05 . Yet the rate of cross-cartel voting for the frustrated Polo-party-preferring voters - represented by $d_{p u}$ - was considerably higher at 0.12 . Because these estimates also had very narrow bounds as indicated by the confidence intervals, it can be confidently stated from these results that more than twice as much cross-cartel voting took place among frustrated Polo supporters as among frustrated Ulivo supporters.

The frustrated Ulivo voters also showed greater cohesion in avoiding defections to the noncartel candidates. Our estimates show that at the aggregate level, the proportion of

\footnotetext{
${ }^{10}$ We estimated the model without priors and did not set starting values for the covariates. The model tended to have computational problems in the EI2 stage, requiring us to turn off the multiple imputation feature in the EI software (version 1.5, 5/5/2002) for the EI2 procedure (by setting _EI2_m = -1). The EI manual states that this will result in somewhat smaller standard errors for the simulated parameters, but does not indicate the extent of this effect.

${ }^{11}$ The $95 \%$ confidence intervals were computed by taking the middle $95 \%$ of the sorted aggregate transformed quantities, computed from the simulations of the aggregate quantities through algebraic transformation as described in the previous section.
} 


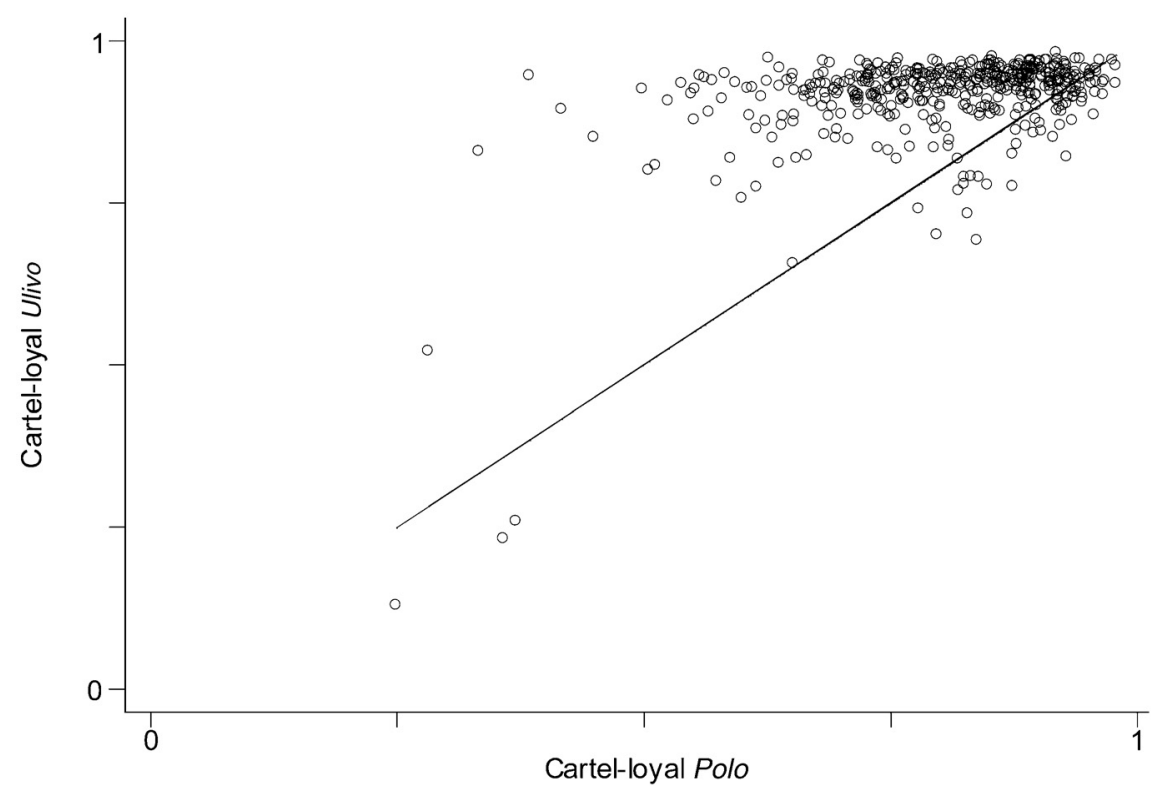

Figure 14.2. Direct comparison of district-level estimates of cartel-loyal voting, Ulivo versus Polo.

frustrated Ulivo supporters voting for a noncartel ("other") candidate was approximately 0.04, compared to an estimated aggregate proportion of 0.07 for Polo. Once again, the proportion of frustrated cartel voters defecting to vote for a noncartel candidate was more than twice as great for Polo as for Ulivo, with the $95 \%$ confidence intervals indicating these estimates to be quite precise.

A graphic summary of the district-level results is provided in Figures 14.1 and 14.2. Figure 14.1 depicts all of the estimated precinct quantities in boxplots, pairing the analogous Ulivo and Polo quantities for comparison. The boxes depict the interquartile range, with the median value represented by the line in the middle of the box. The whiskers represent the minima and maxima of the range of precinct-level point estimates. In Figure 14.1, the top two bars compare the degree of cartel loyalty among frustrated Ulivo and Polo voters. The results are consistent with the aggregate values reported in Table 14.5. The median for the Polo cartel-loyal voters is clearly lower than the corresponding Ulivo value, also having a dramatically wider range (measured by the interquartile range shown by the box). The difference between the cross-cartel voters is even more dramatic. Far fewer frustrated Ulivo supporters voted for a Polo candidate than vice versa. Furthermore, the degree of discipline among frustrated Polo voters that did not vote with their cartel was much lower, indicated by the much greater range of the district estimates for the frustrated Polo-voting Ulivo voters. Finally, the number of frustrated Ulivo-voting others was also lower than in typical precinct for Polo supporters, with a greater variance as well.

Figure 14.2 compares cartel loyalty directly at the precinct level among Poloand Ulivo cartel voters. Each small circle in the scatterplot represents a precinct-level estimate of $\left(Y_{p}, Y_{u}\right)$. As can be seen, in the vast bulk of precincts, the level of cartel loyalty among Ulivo voters was much higher, to the upper right of the 45-degree line. For the four districts with much smaller levels of both Ulivo and Polo cartel loyalty, our examination of these in the data set reveals that there were unusually popular noncartel candidates competing, three of the four coming from a specific region. The fourth candidate was an extremely popular noncartel 
incumbent, depressing the rates of cartel loyalty on both sides but more so for Ulivo. It is precisely these sorts of effects that in the absence of covariates would cause aggregation bias, but that can largely be controlled by introducing independent information about the partisanship and incumbency of specific noncartel candidates, as well some geographically specific information.

\section{Interpretation}

Our overall finding is that the Ulivo cartel had a higher degree of general voter loyalty than the Polo cartel - with Polo losing more far more voters to the Ulivo cartel than vice versa. This is quite consistent with our knowledge of Italian politics in the 1990s. First and foremost, in 1994 the Italian political scene was dramatically changed by the entry of a new party, Forza Italia (FI) and its controversial leader Silvio Berlusconi, a media tycoon who was able to build a party in just a few months and gain spectacular success in the 1994 election. While the strong leadership of Berlusconi was successful in assembling the coalition partners in the Polo cartel at the elite level, we may conjecture that his charismatic appeal - being strongly divisive - failed to capture many of the disappointed Polo supporters at the voter level.

Second, in 1996 the Polo cartel built a single nationwide alliance for the first time. In 1994 there had been two electoral alliances: one formed by FI and the Northern League in the north, and one formed by FI and AN in the south. This could also have led to lower cartel loyalty within the Polo coalition. On the other hand, the Ulivo coalition was composed of more traditional parties and allies who would have been expected to have more capacity of coordinating their voters on a more instrumental choice. In sum, the higher proportion of expressive voters in the Polo cartel is very consistent with our initial expectations.

\section{El Diagnostics}

We have discussed our results in general substantive terms, but it is also worthwhile to assess these results by examining some of the characteristics of the data and some intermediate results from the parametric EI procedure. Table 14.6 in the Appendix reports the maximumlikelihood estimates for the covariates from both the EI and EI2 estimations. These values themselves contain a great variety of substantively important information, but we leave the task of interpreting them to future work, having intended primarily to use them to control aggregation bias. But it is to our satisfaction that most are highly statistically significant, indicating that did indeed explain variation in the precinct-level parameter estimates in our data set.

Figures 14.3 and 14.4 show additional information about the data and allow us to assess whether it conforms broadly to the checklist of characteristics recommended for successful application of EI. The left panel of Figure 14.3 graphs $X_{i}$ against $T_{i}$ (in this case, the proportion of frustrated Polo voters against the proportion of excess noncartel voters), with the size of the circles proportional to the number of frustrated voters in the district. The results show a fairly uniform distribution along $X$, and a tight clustering along the $T$ dimension, with a single mode, and only two discernable outliers. The right panel shows the tomography plot for the two parameter values $\beta_{i}^{b}$ and $\beta_{i}^{w}$, with the lines indicating where each parameter must lie according to a well-known deterministic accounting identity. The two ovals represent contour plots for mean posterior contours. For the estimation of $\beta_{i}^{b}$ and $\beta_{i}^{w}$, there is clear evidence of some nonhomogenous precincts, indicated by the five stray lines, although most tomography lines were tightly clustered in the upper range of the graph. With covariates to control for the nonhomogenous precincts, the tomography plot reveals no pattern substantially violating the assumptions required for estimation using EI. 


\begin{tabular}{|c|c|c|c|c|}
\hline \multirow[b]{2}{*}{ Covariates } & \multicolumn{2}{|c|}{ El Estimation } & \multicolumn{2}{|c|}{ El2 Estimation } \\
\hline & $\beta^{b}$ & $\beta^{w}$ & $\lambda^{b}$ & $\lambda^{w}$ \\
\hline \multicolumn{5}{|l|}{$Z^{b}$ Covariates } \\
\hline Constant & 2.0713 & 0.2164 & 2.4320 & 0.2087 \\
\hline Ulivo competitiveness & -0.7416 & 0.1308 & -0.0887 & 0.2045 \\
\hline Polo competitiveness & -0.4301 & 0.2776 & -0.0729 & 0.2046 \\
\hline Ulivo-Polo competitiveness & -0.1598 & 0.2657 & 0.0819 & 0.0139 \\
\hline Northern district $(0 / 1)$ & -0.0173 & 0.2219 & -0.1612 & 0.0443 \\
\hline Northern League candidate $(0 / 1)$ & 0.2262 & 0.0449 & 0.1294 & 0.0570 \\
\hline Communist candidate $(0 / 1)$ & 0.3064 & 0.2955 & -0.1266 & 0.0968 \\
\hline Neo-fascist candidate $(0 / 1)$ & -0.0212 & 0.2267 & -0.0793 & 0.0102 \\
\hline Ulivo incumbent (0/1) & -0.0692 & 0.2260 & 0.0662 & 0.2081 \\
\hline Polo incumbent (0/1) & -0.0807 & 0.1285 & -0.0097 & 0.2037 \\
\hline Other incumbent $(0 / 1)$ & -0.0906 & 0.0549 & -0.1480 & 0.2933 \\
\hline \multicolumn{5}{|l|}{$Z^{w}$ Covariates } \\
\hline Constant & -2.0557 & 0.1159 & 2.6610 & 0.0909 \\
\hline Ulivo competitiveness & -0.0125 & 0.0345 & -0.0902 & 0.0924 \\
\hline Polo competitiveness & -0.0391 & 0.1278 & -0.0880 & 0.0531 \\
\hline Ulivo-Polo competitiveness & 0.0565 & 0.0555 & 0.0690 & 0.0572 \\
\hline Northern district $(0 / 1)$ & 0.0271 & 0.2232 & -0.1809 & 0.0365 \\
\hline Northern League candidate $(0 / 1)$ & -0.0481 & 0.0196 & 0.1854 & 0.0597 \\
\hline Communist candidate $(0 / 1)$ & 0.0989 & 0.0412 & -0.1222 & 0.1663 \\
\hline Neo-fascist candidate $(0 / 1)$ & 0.0237 & 0.0583 & -0.0096 & 0.0111 \\
\hline Ulivo incumbent $(0 / 1)$ & 0.0430 & 0.0460 & 0.0784 & 0.1000 \\
\hline Polo incumbent $(0 / 1)$ & 0.0129 & 0.1505 & -0.0115 & 0.0060 \\
\hline Other incumbent $(0 / 1)$ & 0.0171 & 0.0465 & -0.2050 & 0.0690 \\
\hline$\sigma^{b}$ & -1.8847 & 0.1161 & -2.3770 & 0.2609 \\
\hline$\sigma^{w}$ & -2.9450 & 0.2701 & -2.2720 & 0.2880 \\
\hline$\rho$ & -0.4115 & 0.2900 & 2.0000 & 0.3930 \\
\hline
\end{tabular}

Figure 14.4 displays the same set of graphic diagnostics for the second-stage estimation of $\lambda_{i}^{b}$ and $\lambda_{i}^{w}$. Here the patterns are also quite well behaved, with the $X_{i}-T_{i}$ graph showing a clear linear pattern (here $X_{i}$ is a plot of the estimated proportion of frustrated Polo voters staying with a cartel candidate, with estimates come from the first-stage EI procedure, against the proportion of excess cartel voters represented in EI notation as $T_{i}$ ). Similarly, the mean posterior contours from the tomography plot fall generally around the mode of the intersecting tomography lines. There is nothing in these diagnostics to lead us to suspect that EI would yield unreliable estimates.

\section{DISCUSSION}

Our estimation of vote splitting in Italy's mixed-member electoral system provides a clear example of how statistical techniques for ecological inference can be used in multiparty contexts to estimate individual-level parameters when only aggregate data is observed. By proceeding from a very general discussion to modeling the vote-splitting problem in a specific context, and then formulating a specific parameterization for estimating vote splitting, we have illustrated how such modeling is performed and what steps and choices are required to 


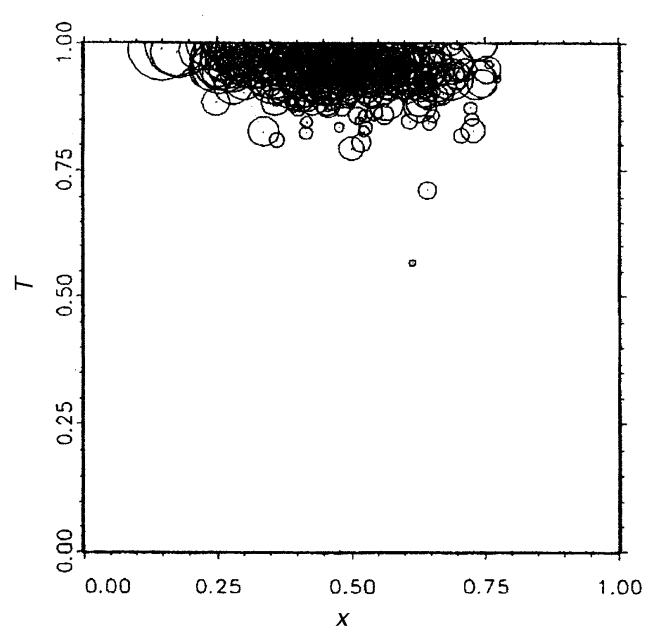

(a)

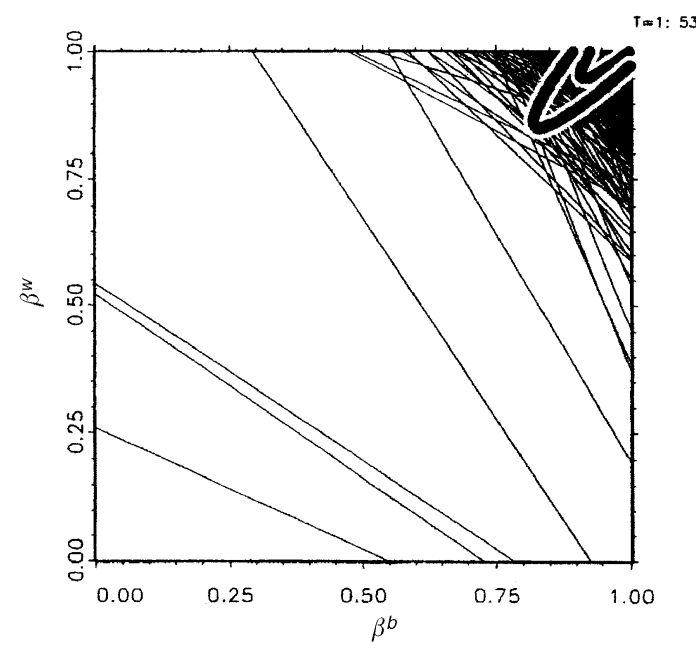

(b)

Figure 14.3. Graphs of fit for EI estimation of $\beta^{b}, \beta^{w}$.

yield the desired results. The Italian example is somewhat unusual in that its organization into electoral cartels makes possible a significant reduction of the parameter space, something required for the successful application of the EI method used here. But other systems also feature political or institutional arrangements reducing the number of unknowns in splitticket voting problems to more tractable dimensions. Examples would be the reduction by political brokering to just two candidates of the top-three runoff system in the Hungarian electoral system (Benoit, 2001), or the reduction by institutional means to just two candidates in more restrictive runoff systems, as used in the French and numerous other presidential elections around the world.

More general applications of ecological inference to multiparty voter transition problems will depend on methodological advances in the estimation of $R \times C$ tables (where $R>2$, $C>2$ ). Interesting work on this problem has taken place recently on several fronts, including the use of entropy-maximizing methods (Johnston and Pattie, 2000), information-theoretic

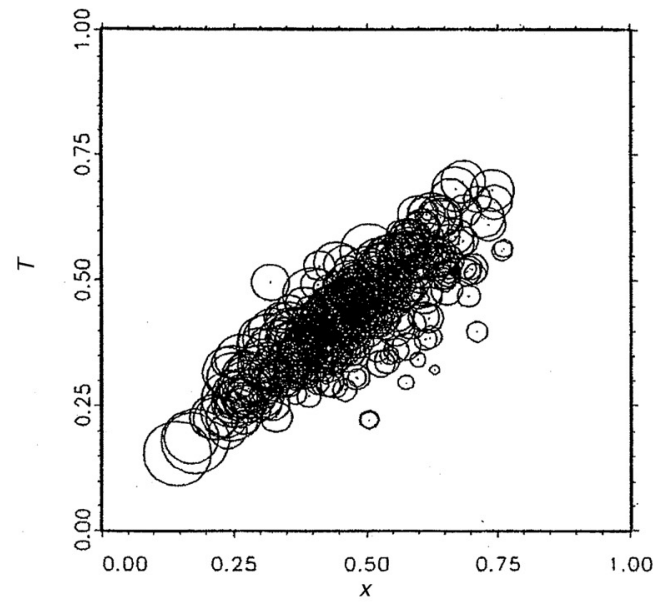

(a)

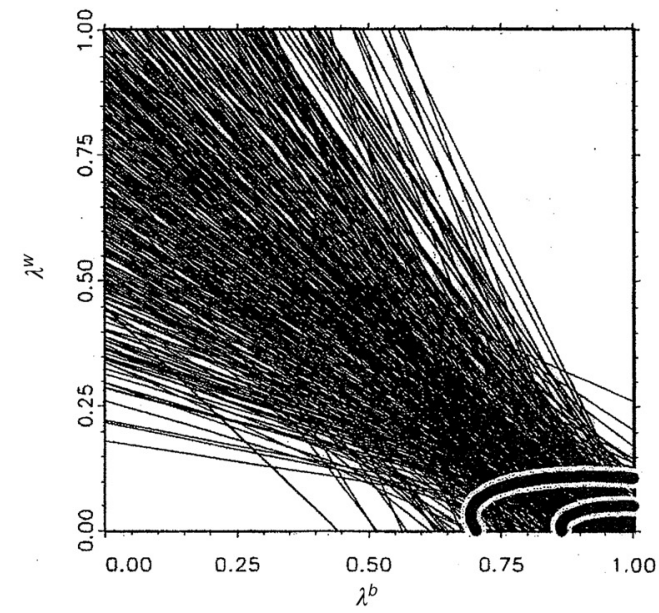

(b)

Figure 14.4. Graphs of fit for E12 estimation of $\lambda^{b}, \lambda^{w}$. 
approaches (Judge, Miller, and Cho, this book, Chapter 7), and parametric extensions of EI using Markov-chain Monte Carlo methods (Rosen, Jiang, King, and Tanner, 2001). These methods, however, remain either difficult to implement practically (e.g., the MCMC method) or largely untested in well-known empirical contexts. Because each additional dimension places greater demands on the data, modeling issues such as distributional assumptions, priors, and covariates assume tremendous importance in the estimation of $R \times C$ ecological inference problems. Greater understanding and experience is needed in the application of $R \times C$ methods - both in a controlled context and in empirical settings where a large amount of contextual information is known in advance by the researcher before genuine practical advances in split-ticket voting estimation in multiparty contexts can be made.

Our examination here of split-ticket voting in the 1996 Italian elections has also yielded some important substantive findings. First, we have demonstrated that the Ulivo cartel was more successful in maintaining voter loyalty and cartel discipline between the list ballot and the relatively recent institution of single-member district voting. Taking "frustrated" to mean those voters whose most-preferred party was by cartel agreement not allowed to field a single-member district candidate, we found that frustrated Ulivo supporters were much more likely to vote instrumentally than their frustrated Polo counterparts. Frustrated Polo supporters were also much more likely to vote for an Ulivo candidate than vice versa. These findings were not only firmly in accord with our substantive political knowledge of the Italian case, but also largely confirmed by the election result itself.

Finally, while we did not focus here on the results of the covariate estimations (see Appendix), we also found strong evidence that precinct-level voting varies systematically with a number of precinct-level variables. First, cartel-disloyal voting decreases when competition between cartels is more intense. Second, cartel-disloyal voting increases when competition within a cartel is more intense and when the cartel is more evenly fragmented. Finally, the presence of extreme left Communist candidates tended to drive voters away from the leftist Ulivo cartel and increase the level of disloyal voting. Finally, the presence of incumbent candidates, especially noncartel incumbents, tended to attract defectors from other cartels and to increase within-cartel loyalty. We have left a fuller discussion of these results for our future work, but the significance of simply having arrived at these estimates should not be understated.

\section{APPENDIX}

Table 14.6 shows the covariate parameter values in scale of estimation.

\section{REFERENCES}

Banducci, S., J. Karp, and J. Vowles. 1998. "Vote Splitting under MMP.” In J. Vowles et al. (eds.), Voters' Victory: New Zealand's First Election under Proportional Representation. Auckland: Auckland University Press.

Beck, Paul Allen. 1997. Party Politics in America, 8th ed. New York: Longman.

Benoit, Kenneth. 2001. "Two Steps Forward, One Step Back: Electoral Coordination in the Hungarian Elections of 1998.” Manuscript Trinity College.

Benoit, Kenneth, Daniela Giannetti, and Michael Laver. 2002. “'Instrumental' and 'Expressive' Voting in Mixed-Member Electoral Systems: Split-Ticket Voting in Italy." Presented at the Conference on Ecological Inference, Center for Basic Research in the Social Sciences, Harvard University, June 17-18, 2002. 
Brennan, Geoffrey and Alan Hamlin. 2000. Democratic Devices and Desires. Cambridge: Cambridge University Press.

Brennan, Geoffrey and Loren Lomaski. 1993. Democracy and Decision. New York: Cambridge University Press.

Burden, Barry C. and David C. Kimball. 1998. "A New Approach to the Study of Ticket Splitting." American Political Science Review, 92: 533-544.

D'Alimonte, Roberto. 1998. Appendix: The Italian elections of 1996. European Journal of Political Research, 34: 171-174.

Fiorina, Morris P. 1996. Divided Government, 2nd ed. Needham Heights, MA: Allyn and Bacon.

Johnston, Ron and Charles Pattie. 1999. "Constituency Campaign Intensity and Split-Ticket Voting: New Zealand's First Election under MMP.” British Journal of Political Science, 21: 95-108.

Johnston, Ron and Charles Pattie. 2000. "Ecological Inference and Entropy-Maximizing: An Alternative Procedure for Split-Ticket Voting." Political Analysis, 8, 4: 333-345.

King, Gary. 1997. A Solution to the Ecological Inference Problem. Princeton: Princeton University Press. Laver, Michael. 1987. “The Logic of Plurality Voting in Multiparty Systems.” In Manfred Holler. (ed.), The Logic of Multiparty Systems. Dordrecht: Kluwer Academic Publishers.

Moser, Robert G. 1999. "Electoral Systems and the Number of Parties in Postcommunist States." World Politics, 51: 359-384.

Reed, Stephen and Michael F. Thies. 2001. "The Causes of Electoral Reform in Japan.” In Shugart and Wattenberg (2001b).

Rosen, Ori, Wenxin Jiang, Gary King, and Martin A. Tanner. 2001. "Bayesian and Frequentist Inference for Ecological Inference: the $R \times C$ Case.” Statistica Neerlandica, 55, 2: 134-156.

Schuessler, Alexander A. 2000. A Logic of Expressive Choice. Princeton: Princeton University Press.

Shin, Michael. 2001. “The Politicization of Place in Italy." Political Geography, 20: 331-352.

Shin, Michael E., and John Agnew. 2001. "The Geography of Party Replacement in Italy, 1987-1996.” Political Geography, 21: 221-242.

Shugart, Matthew S. and Martin P. Wattenberg. 2001a. "Mixed-member Electoral Systems: A Definition and Typology." In Shugart and Wattenberg (2001b).

Shugart, Matthew S. and Martin P. Wattenberg (eds.). 2001b. Mixed-Member Electoral Systems: The Best of Both Worlds? Oxford: Oxford University Press.

Strøm, Kaare, Ian Budge, and Michael Laver. 1994. "Constraints on Cabinet Formation in Parliamentary Democracies." American Journal of Political Science, 38, 2: 303-335.

Tsebelis, George. 1988. "Nested Games: The Cohesion of the French Coalitions." British Journal of Political Science, 18, April: 145-170. 